\title{
Avaliação da proliferação de células endoteliais a partir de fatores de crescimento secretados por células de mieloma múltiplo
}

\section{Assessment of endothelial cells proliferation from growth factors secreted by cells of multiple myeloma}

\author{
Paula Dayana Matkovski \\ Universidade Estadual de Ponta Grossa - UEPG - Ponta Grossa - Brasil \\ pauladayana@gmail.com \\ Evelyn Assis de Andrade \\ Universidade Estadual de Ponta Grossa - UEPG - Ponta Grossa - Brasil \\ evelyn.aandrade@gmail.com \\ Giovani Marino Favero \\ Universidade Estadual de Ponta Grossa - UEPG - Ponta Grossa - Brasil \\ gmfavero@uepg.br
}

\section{Resumo}

O mieloma múltiplo é uma neoplasia maligna das células $B$, que para sua sobrevivência, assim como outros tumores, necessita formar novos vasos sanguíneos, em um processo conhecido como angiogênese, o qual é regulado através de mecanismos parácrinos e autócrinos por fatores de crescimento e citocinas. Este trabalho tem como objetivo avaliar o estímulo proliferativo dos fatores de crescimento derivados de cultura celular de mieloma múltiplo, sobre células endoteliais de aorta de coelho. As células endoteliais (RAEC), bem como as células do mieloma (RPMI 8226) foram cultivadas em frascos de cultura contendo meio RPMI 1640 suplementado com 10\% de Soro Fetal Bovino (SFB) e mantidas em incubadora de tensão de $\mathrm{CO}_{2}$ a $5 \%$ e $37^{\circ} \mathrm{C}$. A avaliação da proliferação e viabilidade das células endoteliais foi realizada através do método Azul de Tripan para os grupos controle e para aqueles contendo 50,100 e $300 \mu \mathrm{L}$ de sobrenadante de cultura de mieloma, nos tempos de 24, 48 e 72 horas. As quantificações de citocinas e fatores de crescimento presentes na cultura celular de mieloma múltiplo foram realizados através do método de ELISA. O sobrenadante de mieloma contendo as citocinas não apresentou in vitro a capacidade de aumentar a proliferação das células endoteliais como ocorre in vivo. Os fatores encontrados em maior quantidade na amostra relacionam-se diretamente com o microambiente tumoral, promovendo a angiogênese e ativando vias de sinalização antiapoptóticas, o que resulta na migração e proliferação das células endoteliais e sobrevivência da massa tumoral.

Palavras-chave: VEGF, angiogênese, microambiente tumoral.

\section{Abstract}

Multiple myeloma is a malignancy of B cells, which for its survival, as well as other tumors, needs to form new blood vessels in a process known as angiogenesis, which is regulated by autocrine and paracrine mechanisms by growth factors and cytokines. This study aims 
to evaluate the proliferative stimulus of growth factors derived from cell culture of multiple myeloma, on endothelial cells of rabbit aorta. Endothelial cells (RAEC) and myeloma cells (RPMI 8226) were grown in culture flasks containing RPMI 1640 supplemented with 10\% fetal calf serum (FCS) and kept in an incubator voltage $5 \% \mathrm{CO}_{2}$ and $37 \stackrel{\circ}{\circ}$. The assessment of viability and proliferation of endothelial cells was performed using the method Trypan blue for control groups and those containing 50, 100 and $300 \mu \mathrm{L}$ of culture supernatant of myeloma, at 24, 48 and 72 hours. Quantification of cytokines and growth factors present in multiple myeloma cell culture was performed using the ELISA method. The myeloma supernatant containing the cytokine in vitro showed no ability to increase proliferation of endothelial cells as occurs in vivo. The factors found in larger amounts in the sample relate directly to the tumor microenvironment, promoting angiogenesis and signaling pathways activating anti-apoptotic, resulting in the migration and proliferation of endothelial cells and survival of tumor mass.

Keywords: VEGF, angiogenesis, tumor microenvironment.

\section{Introdução}

O Mieloma Múltiplo (MM) é uma neoplasia das células $\mathrm{B}$, caracterizado pelo acúmulo de plasmócitos malignos no interior da medula óssea, em íntimo contato com as células do estroma, que secretam fatores e citocinas, os quais promovem o crescimento e sobrevivência das células tumorais. Entre os fatores e citocinas produzidos pelo microambiente do mieloma, a secreção parácrina de interleucina-6 (IL-6) na medula óssea promove a proliferação das células neoplásicas e protege contra a citotoxicidade induzida por drogas (CHAUHAN et al., 1996; HIDESHIMA et al., 2004). Através da interação com o estroma, as células do mieloma também estimulam a produção de citocinas que apóiam a osteoclastogênese e a angiogênese (HAYASHI; HIDISHIMA; ANDERSON, 2003).

O mieloma apresenta células com alto grau de anaplasia e que podem ter a morfologia de um pequeno linfócito, um linfoblasto, ou um plasmócito. Com a progressão da doença, a população de plasmoblastos aumenta e nos estágios finais, podem representar a população dominante do tumor (BEUTLER et al., 1995). A maturidade dos plasmócitos e o grau de infiltração estão significativamente envolvidos com a sobrevida do paciente (HENRY, 1999).

A produção normal de imunoglobulinas gera uma quantidade maior de cadeias leves em relação às cadeias pesadas e em decorrência da produção exacerbada de imunoglobulinas em pacientes com MM, as cadeias leves, denominadas de proteínas de Bence Jones (PBJ), alcançam níveis significativos no organismo, sendo as principais responsáveis pelo comprometimento renal (COTRAN; KUMAR; ROBBINS, 1991).

As lesões ósseas decorrem da ativação exacerbada de osteoclastos com desequilíbrio nos processos de reabsorção e síntese óssea. Estão envolvidas no processo as células do $\mathrm{MM}$ e do microambiente que sintetizam e secretam fatores ativadores de osteoclastos (FAO), como as interleucinas. Descobertas recentes identificaram importantes sinalizadores no processo de reabsorção óssea, como o ligante do receptor de ativação nuclear kappa $B$ (RANKL), o receptor de ativação nuclear kappa B (RANK), e a osteoprotegerina (OPG), com funções de antagonizar o RANKL. O aumento na expressão de RANKL e a diminuição na expressão de OPG, como ocorrem nos pacientes com $\mathrm{MM}$, desencadeia o processo de reabsorção óssea. A proteína DKKP1, presente em pacientes com MM, também está envolvida com a inibição de osteoblastos (HUNGRIA, 2007).

A célula tumoral desenvolve vias de sinalização responsáveis por mantê-la viva. Essa sinalização pode ser através de um mecanismo direto, também denominado autócrino, ou por um mecanismo indireto, denominado parácrino. Na sinalização 
autócrina, a própria célula tumoral produz um fator que age sobre o mesmo tipo de célula neoplásica. Enquanto na sinalização parácrina, a célula cancerígena secreta um fator que age nas proximidades do ambiente tumoral, como é o caso do fator de crescimento endotelial vascular (VEGF) que interage com as células endoteliais. As células endoteliais do vaso-mãe também são estimuladas pelas citocinas tumorais em um processo parácrino.

A interação presente no microambiente tumoral é um fator importante para a proliferação angiogênica, sendo o estudo deste estímulo imprescindível para melhor compreensão da relação parênquima-estroma em ambientes tumorais. Este trabalho tem como objetivo avaliar o estímulo proliferativo dos fatores de crescimento derivados de cultura celular de mieloma múltiplo, sobre células endoteliais de aorta de coelho.

\section{Metodologia}

\subsection{Cultivo Celular - Linhagem de Mieloma Múltiplo (RPMI 8226)}

A linhagem RPMI 8226 é uma linhagem de MM humana, oriunda de sangue periférico e foi estabelecida em 16/06/1966 por Moore e Kitamura no Roswell Park Memorial Institute. Trata-se da linhagem de MM mais bem documentada e com considerável estabilidade genética. Tem características fenotípicas de células linfoplasmocitárias, com alto gral de anaplasia e apresenta um tempo de dobramento de 40 a 80 horas. As células de MM RPMI 8226 foram gentilmente doadas pelo Prof. Dr. Sérgio Paulo Bydlowski da Faculdade de Medicina da USP. As células RPMI 8226 foram cultivadas em frascos de cultura contendo $15 \mathrm{~mL}$ de meio RPMI 1640 suplementado com $10 \%$ de Soro Fetal Bovino (SFB), $100 \mathrm{U} / \mathrm{mL}$ de penicilina e $24 \mathrm{mM}$ de $\mathrm{NaHCO}_{3}$. Estas células foram mantidas em incubação com tensão de $5 \%$ de $\mathrm{CO}_{2}$ a $37^{\circ} \mathrm{C}$ até a realização do experimento.

\subsection{Cultivo Celular - Linhagem de Célula Endotelial de Aorta de Coelho (RAEC)}

As células RAEC foram gentilmente doadas pelo pesquisador Dr. João Wosniak Júnior do Instituto do Coração de São Paulo (INCOR). As células foram cultivadas em frascos de cultura contendo $15 \mathrm{~mL}$ de meio RPMI 1640 suplementado com $10 \%$ de SFB, $100 \mathrm{U} / \mathrm{mL}$ de penicilina e $24 \mathrm{mM}$ de $\mathrm{NaHCO}_{3}$. Estas células foram mantidas em incubação com tensão de $5 \%$ de $\mathrm{CO}_{2}$ a $37^{\circ} \mathrm{C}$ até a realização dos experimentos.

\subsection{Quantificação de citocinas e fatores de crescimento}

O sobrenadante armazenado em freezer foi utilizado na quantificação das citocinas e fatores de crescimento através do método de ELISA (Enzyme Linked Immuno Sorbent Assay), em leitora Lab Life MX PN 2001 na faixa de $450 \mathrm{~nm}$ e 450/690 nm. O VEGF e o $\beta$ FGF foram quantificados utilizando-se kit RayBio ${ }^{\circledR}$, enquanto a IL-6 e o TGF- $\beta$ foram quantificados utilizando-se kit eBioscience ${ }^{\circledR}$, segundo a metodologia descrita pelos fabricantes.

\subsection{Proliferação e viabilidade celular pelo método Azul de Tripan}

Foram plaqueadas $7 \times 10^{3}$ células por poço, em placa de 12 poços. O experimento foi realizado em quatro grupos em triplicata: controle (CTL), 50, 100 e $300 \mu \mathrm{L}$ de sobrenadante de cultura celular de mieloma múltiplo. Em cada poço foram adicionados 1 $\mathrm{mL}$ da solução de células e meio RPMI 1640 suplementado com $20 \%$ de SFB até o volume de $3 \mathrm{~mL}$, conforme demonstrado na Tabela 1. 
Tabela 1: Distribuição de meio RPMl com SFB, da solução de células e do sobrenadante de mieloma múltiplo em cada poço das placas, para posterior análise pelo Método Azul de Tripan

\begin{tabular}{cccc}
\hline Poços & $\begin{array}{c}\text { Solução de } \\
\text { células }\end{array}$ & $\begin{array}{c}\text { Meio RPMl 1640 } \\
\text { com 20\% de SFB }\end{array}$ & Sobrenadante de MM \\
Controle (CTL) & $1 \mathrm{~mL}$ & $2 \mathrm{~mL}$ & -- \\
$50 \mu \mathrm{L}$ de sobrenadante & $1 \mathrm{~mL}$ & $950 \mu \mathrm{L}$ & $50 \mu \mathrm{L}$ \\
$100 \mu \mathrm{L}$ de sobrenadante & $1 \mathrm{~mL}$ & $900 \mu \mathrm{L}$ & $100 \mu \mathrm{L}$ \\
$300 \mu \mathrm{L}$ de sobrenadante & $1 \mathrm{~mL}$ & $700 \mu \mathrm{L}$ & $300 \mu \mathrm{L}$ \\
\hline
\end{tabular}

A análise da viabilidade celular foi realizada nos tempos de 24,48 e 72 horas através do método Azul de Tripan. $O$ azul de Tripan é um corante que atravessa a membrana de células inviáveis, corando-as. Para a quantificação das células viáveis e inviáveis presentes em cada poço, $20 \mu \mathrm{L}$ do azul de Tripan foram misturados com $20 \mu \mathrm{L}$ da solução de células contidas no poço, após centrifugação e ressuspensão das mesmas com meio RPMI 1640. A contagem foi feita em hemocitômetro e a análise estatística dos dados obtidos foi realizada pelo método ANOVA, com posterior avaliação por Bonferroni.

\section{Resultados}

\subsection{Quantificação dos fatores de crescimento e citocinas}

Realizou-se a média dos valores obtidos nas quatro medições, de cada fator e citocina de crescimento presentes no sobrenadante de mieloma múltiplo, nas leituras de $450 \mathrm{~nm}$ e 450/690 nm (Tabelas 2 e 3).

Tabela 2: Quantificação das citocinas em leitora ELISA Lab Life MX PN 2001

\begin{tabular}{cc}
\hline Fatores de crescimento/citocinas & Quantificação $(\mathbf{4 5 0} \mathbf{n m})$ \\
VEGF & $0,535-0,523-0,483-0,409$ \\
IL-6 & $0,258-0,198-0,219-0,277$ \\
bFGF & $0,106-0,111-0,109-0,104$ \\
TGF $\beta$ & $0,163-0,184-0,160-0,158$ \\
\hline \multicolumn{2}{c}{ Fonte: Autoria própria (2010) }
\end{tabular}

Tabela 3: Quantificação das citocinas em leitora ELISA Lab Life MX PN 2001

\begin{tabular}{cc}
\hline Fatores de crescimento/citocinas & Quantificação $(\mathbf{4 5 0} / \mathbf{6 9 0} \mathbf{n m})$ \\
VEGF & $0,505-0,488-0,437-0,374$ \\
IL-6 & $0,214-0,152-0,173-0,224$ \\
bFGF & $0,067-0,069-0,070-0,062$ \\
TGF $\beta$ & $0,036-0,050-0,037-0,034$ \\
\hline \multicolumn{2}{r}{ Fonte: Autoria própria (2010) }
\end{tabular}

Com o resultado da média dos valores, pode-se verificar a presença de maiores quantidades de VEGF e IL-6, quando comparados aos outros dois fatores de crescimento (Figuras 1 e 2). 
Figura 1: Quantificação de citocinas e/ou fatores de crescimento secretados pela cultura celular de mieloma múltiplo (RPMl 8226)

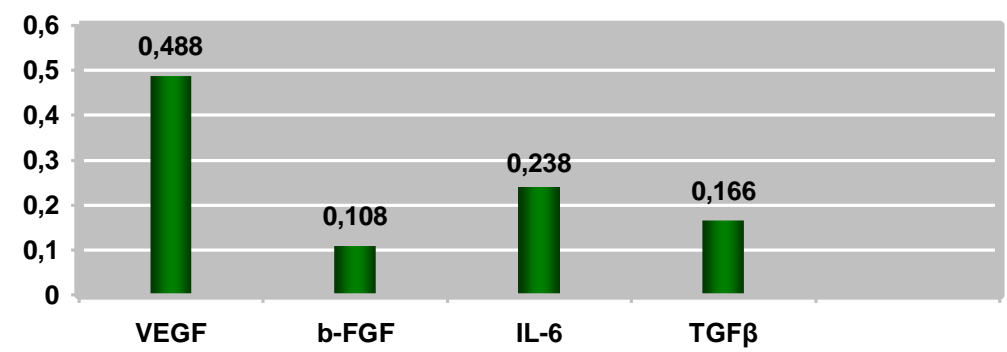

Fonte: Autoria própria (2010)

Os dados demonstrados na Figura 1 foram obtidos por leitura realizada no comprimento de onda de 450 nm e estão apresentados em Unidades de Absorbância (UA).

Figura 2: Quantificação de citocinas e/ou fatores de crescimento secretados pela cultura celular de mieloma múltiplo (RPMI 8226)

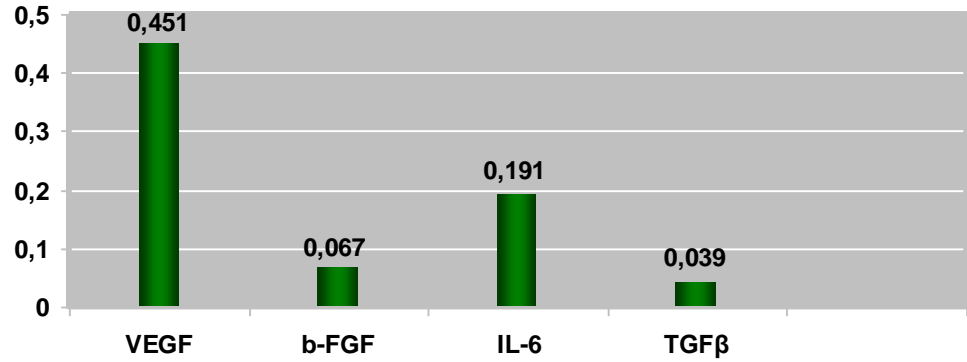

Fonte: Autoria própria (2010)

Os dados demonstrados na Figura 2 foram obtidos por leitura realizada no comprimento de onda de 450/690 nm e estão apresentados em Unidades de Absorbância (UA).

\subsection{Avaliação da proliferação e viabilidade celular in vitro}

$\mathrm{Na}$ Tabela 4 encontram-se os valores da viabilidade de células RAEC obtidos através da contagem em hemocitômetro.

Tabela 4: Contagem das células em hemocitômetro nos tempos de 24, 48 e 72 horas, através do uso do reativo Azul de Tripan

\begin{tabular}{ccccccc}
\hline & $\begin{array}{c}\text { 24 horas } \\
\text { Viáveis }\end{array}$ & $\begin{array}{c}\text { 24 horas } \\
\text { Inviáveis }\end{array}$ & $\begin{array}{c}\text { 48 horas } \\
\text { Viáveis }\end{array}$ & $\begin{array}{c}\text { 48 horas } \\
\text { Inviáveis }\end{array}$ & $\begin{array}{c}\text { 72 horas } \\
\text { Viáveis }\end{array}$ & $\begin{array}{c}\text { 72 horas } \\
\text { Inviáveis }\end{array}$ \\
CTL (1) & 36 & 3 & 56 & 6 & 86 & 17 \\
CTL (2) & 31 & 4 & 65 & 4 & 80 & 7 \\
CTL (3) & 27 & 4 & 44 & 0 & 70 & 6 \\
$50 \mu \mathrm{L}(1)$ & 29 & 3 & 51 & 2 & 97 & 8 \\
$50 \mu \mathrm{L}(2)$ & 31 & 6 & 52 & 3 & 74 & 9 \\
$50 \mu \mathrm{L}(3)$ & 45 & 0 & 63 & 3 & 45 & 5 \\
$100 \mu \mathrm{L} \mathrm{(1)}$ & 35 & 2 & 60 & 3 & 54 & 27 \\
$100 \mu \mathrm{L} \mathrm{(2)}$ & 40 & 4 & 45 & 4 & 58 & 4 \\
$100 \mu \mathrm{L}(3)$ & -- & -- & 45 & 3 & 73 & 3 \\
$300 \mu \mathrm{L}(1)$ & 46 & 6 & 69 & 3 & 65 & 5 \\
$300 \mu \mathrm{L} \mathrm{(2)}$ & 33 & 2 & 51 & 2 & 79 & 3 \\
$300 \mu \mathrm{L}(3)$ & -- & -- & 60 & 5 & 57 & 2 \\
\hline
\end{tabular}

Fonte: Autoria própria (2010) 
Nota-se que não houve diferença significativa na viabilidade celular entre os grupos controle, 50, 100 e $300 \mu \mathrm{L}$ de sobrenadante de mieloma múltiplo (Figura 3). Porém, há uma diferença significativa na inviabilidade do grupo controle, a qual está maior quando comparada aos grupos contendo sobrenadante de mieloma (Figura 4).

Figura 3: Avaliação pelo método Azul de Tripan da viabilidade das células endoteliais de aorta de coelho (RAEC), no grupo controle (CTL) e nos grupos contendo 50, 100 e $300 \mu \mathrm{L}$ de sobrenadante de cultura

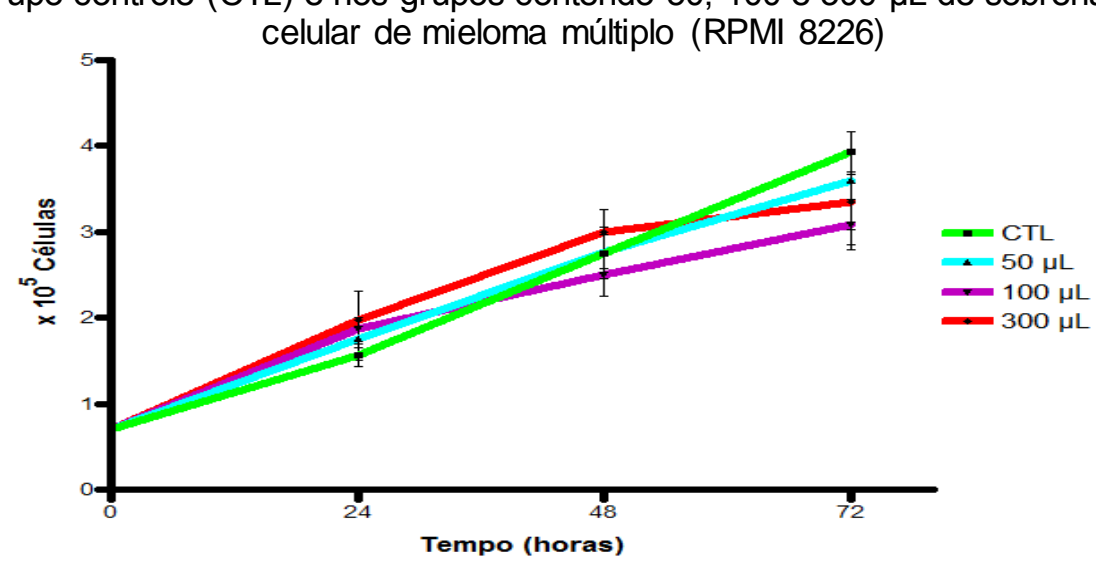

Fonte: Autoria própria (2010)

Figura 4: Avaliação pelo método Azul de Tripan da inviabilidade das células endoteliais de aorta de coelho (RAEC), no grupo controle (CTL) e nos grupos contendo 50 , 100 e $300 \mu \mathrm{L}$ de sobrenadante de cultura celular de mieloma múltiplo (RPMl 8226)

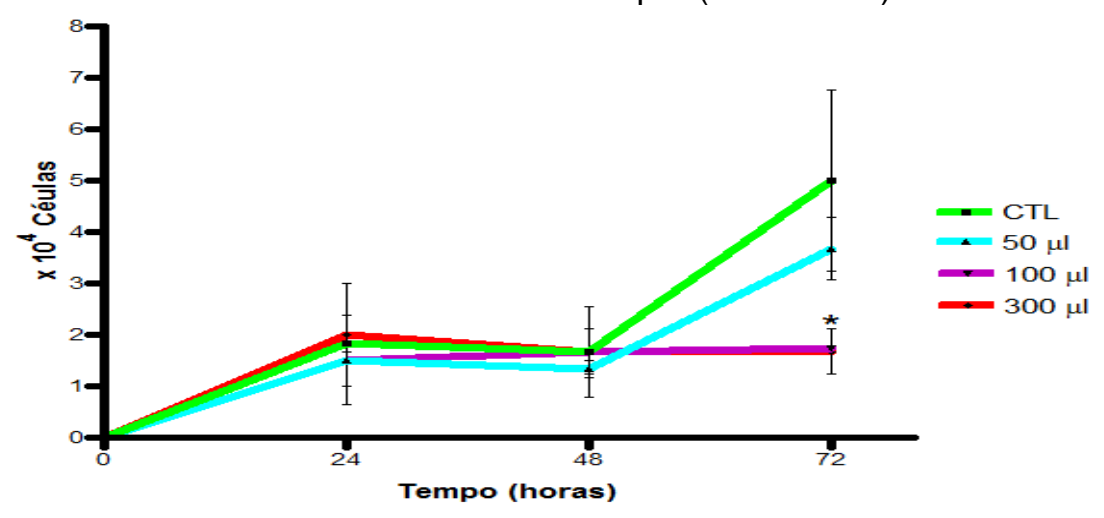

Fonte: Autoria própria (2010)

A análise estatística para as figuras 3 e 4 foi realizada pelo método ANOVA com posterior avaliação por Bonferroni $(p<0,05)$.

Nos poços contendo 50,100 e $300 \mu \mathrm{L}$ de sobrenadante de mieloma múltiplo, as células apresentaram maior capacidade de adesão ao material da placa, quando comparadas com as células dos poços controle. Nos poços contendo sobrenadante de mieloma múltiplo utilizou-se o dobro da tripsina utilizada nos poços controle, permanecendo ainda uma grande quantidade de células aderidas.

\section{Discussão}

Nos estágios iniciais do desenvolvimento, geralmente quando o tumor tem menos de dois milímetros de diâmetro, a nutrição da massa tumoral faz-se essencialmente por difusão a partir dos tecidos vizinhos. Superando esse tamanho, os tumores passam a depender de vasos sangüíneos próprios para que não entrem em degeneração e necrose (SILVA et al., 2007; BRASILEIRO FILHO; GUIMARÃES; BOGLIOLO, 2000; BERGERS, 1999). Conseqüentemente, há a necessidade de que novos vasos sangüíneos sejam 
formados para que haja a nutrição e oxigenação destas células, bem como a eliminação de metabólitos.

No processo angiogênico, a lâmina basal dos vasos sanguíneos é degradada pela ação de proteases da matriz extracelular. As células endoteliais migram então para 0 estroma perivascular, proliferam e iniciam o brotamento capilar. A direção da migração é apontada para a fonte dos estímulos angiogênicos (células neoplásicas). O broto formado expande e assume a forma tubular e uma nova lâmina basal se desenvolve. A proliferação endotelial permite a extensão dos túbulos microvasculares que se unem por anastomose e dão origem à cadeia circulatória funcional (SILVA et al., 2007; LIOTTA; STEEG; STELLER-STEVENSON, 2001). Ocorre então um aumento da densidade microvascular na medula óssea, a qual é induzida pelo VEGF secretado pelas células do mieloma e do estroma medular. Essa produção de VEGF decorre do estímulo direto da IL6 produzida pelas células do microambiente, o que proporciona a sobrevida dos plasmócitos neoplásicos. O VEGF também atua de forma recíproca, estimulando a produção de IL-6 e o crescimento tumoral (PEREIRA et al., 2008; ZHANG et al., 2005).

$\mathrm{O}$ equilíbrio existente entre os fatores pró-angiogênicos e anti-angiogênicos pode ser afetado através da formação de células neoplásicas, que ocasionam a secreção de citocinas (interleucinas) e fatores de crescimento (VEGF, bFGF e TGF $\beta$ ), que por sua vez, ativam a formação de novos vasos sanguíneos, sendo então denominados fatores próangiogênicos. Em contrapartida, existem certas proteínas responsáveis pelo controle do ciclo celular, como a p53, p21, CDKs e ciclinas. Os genes que codificam essas proteínas são denominados genes supressores de tumor. Isso se deve ao fato dessas proteínas bloquearem a divisão celular, caso verifiquem falhas na duplicação e transcrição do DNA, causadas por mutações. Tais proteínas inibem a proliferação celular, e de maneira indireta e direta, inibem o surgimento de novos vasos sanguíneos e o desenvolvimento de neoplasias. Em muitos tumores, esses genes supressores de tumor são perdidos ou inativados, implicando a perda da regulação da proliferação celular, contribuindo para 0 crescimento de células tumorais (PEREIRA et al., 2008; COOPER, 2001). Outro mecanismo regulador do ciclo celular é a apoptose, que também pode provocar a morte da célula em detrimento da mesma estar mutada (SILVA et al, 2007). O mieloma múltiplo provoca uma superexpressão do gene $\mathrm{Bcl} 2$, que tem atividade anti-apoptótica. Conseqüentemente, este tumor consegue "driblar" a cascata de reações que levam à morte celular. Qualquer que seja a sua causa, o câncer é essencialmente uma doença de células caracterizada por um defeito nos mecanismos de controle dos processos de proliferação e diferenciação celular.

A partir do experimento, pode-se observar que não houve diferença significativa na viabilidade celular entre os grupos controle, 50, 100 e $300 \mu \mathrm{L}$ de sobrenadante de mieloma múltiplo (Figura 3). Tal resultado permite concluir que o sobrenadante contendo os fatores e citocinas não apresentou in vitro a capacidade de aumentar a proliferação das células endoteliais como ocorre in vivo, o que pode ser justificado pelo fato de ter ocorrido uma maior capacidade de adesão das células endoteliais nos poços contendo o sobrenadante, como foi observado no experimento. Consequentemente, estas células que permaneceram aderidas nas placas - células viáveis - não fizeram parte da contagem no hemocitômetro, diminuindo assim a quantificação de células viáveis presentes nos poços contendo sobrenadante (Figura 3). Porém, a inviabilidade do grupo controle mostrou-se significativamente maior quando comparada aos grupos contendo 100 e $300 \mu \mathrm{L}$ de sobrenadante de mieloma (Figura 4), a qual traduz a morte de um maior número de células endoteliais quando não existe a presença do sobrenadante tumoral. Esta maior quantidade de células endoteliais e a presença de moléculas de adesão favorecem a formação dos vasos sanguíneos e o crescimento do tumor. Da mesma maneira, os fatores de crescimento e citocinas encontrados no sobrenadante do experimento (Figuras 1 e 2) relacionam-se diretamente com o microambiente tumoral, promovendo a 
angiogênese e ativando vias de sinalização anti-apoptóticas, o que resulta na migração e proliferação das células endoteliais e sobrevivência da massa tumoral (ZHANG; BATAILLE; WIDJENES, 1992).

O fator de crescimento do endotélio vascular (VEGF) está presente durante toda a vida do tumor, sendo ele essencial e fator primário no desenvolvimento do mesmo. À medida que a massa tumoral multiplica-se são ativados fatores secundários relacionados com a angiogênese, como as citocinas e outros fatores de crescimento: fator de crescimento fibroblástico beta ( $\beta F G F$ ) e fator transformador de crescimento beta (TGF $\beta$ ). Porém, o VEGF continua sendo o principal fator pró-angiogênico nos tumores. Este fator possui uma série de receptores específicos que podem estar presentes na membrana de determinadas células, como as células endoteliais. Existem também vários tipos de ligantes VEGF, sendo que aquele diretamente ligado com a angiogênese é o VEGF-A que interage com o receptor VEGFR-2, provocando a migração, proliferação e sobrevivência das células endoteliais, aumentando a permeabilidade vascular tumoral e permitindo 0 recebimento de nutrientes e oxigênio pela massa neoplásica. O receptor VEGFR-2 está presente na maioria das células endoteliais, podendo ser expresso em algumas células tumorais. As outras variantes do receptor e do ligante VEGF estão relacionadas a processos secundários, como a linfangiogênese. É importante destacar que a atividade do VEGFR-2 pode ser influenciada positivamente ou negativamente pela co-expressão e ativação de VEGFR-1 e VEGFR-3 (PEREIRA et al., 2008; BRASILEIRO FILHO; GUIMARÃES; BOGLIOLO, 2000).

As células tumorais têm desenvolvido uma variedade de mecanismos para evitar a resposta imune. Um destes mecanismos envolve a inibição de células dendríticas (células apresentadoras de antígenos) que estimulam as células $B$ e células $T$. $O$ fator de crescimento do endotélio vascular (VEGF) pode impedir a maturação funcional das células dendríticas a partir de seus progenitores hematopoiéticos. Dessa maneira, a secreção de VEGF pelo tumor pode desempenhar um importante papel na supressão da resposta imunológica antitumoral. Outro mecanismo inclui o TGF $\beta$, que elimina as células B e T através da inibição da via de sinalização autócrina de interleucina-2 (IL-2) (URASHIMA et al., 1996).

A citocina predominante no sobrenadante (interleucina-6) liga-se a proteínas transmembrana (gp130) presentes na superfície de algumas células, desencadeando a ativação da via $\mathrm{PI3K} / \mathrm{mTOR} / \mathrm{p} 70$ S6K que resulta na angiogênese, além de ter ação direta sobre os inibidores das proteínas reguladoras do ciclo celular, inibindo os sinais próapoptóticos. A IL-6 também age induzindo sinais anti-apoptose, através da transcrição aumentada do gene Bcl2 (função anti-apoptótica) e inibidores de caspase (ISHIKAWA et al., 2006). Essa sinalização também promove a secreção autócrina de VEGF pelos plasmócitos, que regula a produção de citocinas e a expressão das moléculas de adesão (UCHIYAMA et al., 1992). A IL-6 poder ser produzida em resposta a fatores secretados pelas células do mieloma, como RANKL, TGF $\beta$ e fatores produzidos pelas células do estroma, como VEGF e HGF (DANKBAR et al., 2000; LAUTA et al., 2001). Tanto a interleucina-6 quanto a interleucina-11 têm sido relatadas como estímulos para o crescimento das células do mieloma (ISHIKAWA et al., 2006).

Várias drogas têm sido estudadas como terapia antiangiogênica. Da mesma maneira, diferentes inibidores diretos e indiretos do receptor de VEGF estão sob investigação para o tratamento de tumores sólidos e neoplasias hematológicas. Estas drogas podem bloquear a via de sinalização do VEGF/VEGFR por competitividade (agentes biológicos, anticorpos anti-VEGF/VEGFR e inibidores de transcrição do VEGF) (PEREIRA et al., 2008; PODAR; ANDERSON, 2005).

A talidomida está inclusa no grupo de drogas que agem diretamente sobre as células endoteliais. Por sua capacidade antiangiogênica e de interação com o microambiente tumoral, a mesma tem sido usada em casos de mieloma múltiplo refratário 
e/ou resistente (PEREIRA et al., 2008; PODAR; ANDERSON, 2005). Pesquisas realizadas em busca de novos análogos da talidomida, que apresentassem uma maior potência, mas menor toxicidade em comparação com a mesma, resultaram na síntese de lenalidomida e pomalidomida, duas drogas imunomodulatórias (IMiDs) (QUACH et al, 2010). Talidomida, lenalidomida e pomalidomida podem também aumentar a proliferação das células NK, resultando na morte subseqüente das células do MM na presença de IL-2 (DAVIES et al., 2001).

\section{Conclusão}

Os resultados obtidos demonstram que o sobrenadante da cultura de mieloma múltiplo levou a morte um menor número de células endoteliais quando comparado ao grupo controle, bem como foi capaz de aumentar a capacidade de adesão das mesmas. Em conclusão, os resultados, juntamente com os fatores encontrados na quantificação por ELISA, estão diretamente relacionados com a angiogênese e a sobrevivência da massa tumoral, o que ressalta a importância da terapia antiangiogênica como alvo de pesquisas cada vez mais profundas.

\section{Referências}

BERGERS, G.; et al. Effects of angiogenesis inhibitors on multistage carcinogenesis in mice. Science, v. 284, p. 808-812, apr.1999.

BEUTLER, E.; et al. Williams Hematology, ed. 5, McGraw-Hill: New York, 1995.

BRASILEIRO FILHO, G.; GUIMARÃES, R. C.; BOGLIOLO, L. Distúrbios do crescimento e da diferenciação celular. Patologia, Rio de Janeiro: Guanabara Koogan, v. 6, p.149-193, 2000.

CHAUHAN, D.; et al. Multiple myeloma cell adhesion-induced interleukin- 6 expression in bone marrow stromal cells involves activation of NF-nB. Blood, v. 87, p. 1104-1112, feb. 1996.

COOPER, G. M. A Célula: Uma Abordagem Molecular. 2 ed. Porto Alegre: Artmed, 2001.

COTRAN, R. S.; KUMAR, V.; ROBBINS, A. L. Patologia: estrutural e funcional. 4 ed. Rio de Janeiro: Guanabara Koogan, 1991.

DANKBAR, B.; et al. Vascular endothelial growth factor and interleukin-6 in paracrine tumor-stromal cell interactions in multiple myeloma. Blood, v. 95, p. 2630-2636, apr. 2000.

DAVIES, F. E.; et al. Thalidomide and immunomodulatory derivatives augment natural killer cell cytotoxicity in multiple myeloma. Blood, v. 98, p. 210-216, 2001.

HAYASHI, T.; HIDISHIMA, T.; ANDERSON, K. C. Novel therapies for multiple myeloma. British Journal of Haematology, v. 120, p. 10-17, oct. 2003.

HENRY, J. B. Diagnósticos Clínicos e Tratamento por Métodos Laboratoriais. 2 ed. São Paulo: Manole, 1999. 
HIDESHIMA, T.; et al. Advances in biology of multiple myeloma: clinical applications. Blood, v. 104, p. 607-618, aug. 2004.

HUNGRIA, V. T. M. Doença óssea em Mieloma Múltiplo. Revista Brasileira de Hematologia e Hemoterapia, v. 29, n. 1, p. 60-66, 2007.

ISHIKAWA, H.; et al. Mitogenic signals initiated via inteleukin-6 receptor complexes in corporation with other transmembrane molecules in myelomas. Journal of Clinical and Experimental Hematopathology; v. 46, p. 55-66, nov. 2006.

LAUTA, V. M.; et al. Interleukin- 6 and the network of several cytokines in multiple myeloma: an overview of clinical and experimental data. Cytokine, v. 16, p. 79-86, 2001.

LIOTTA, L. A.; STEEG, P. S.; STELLER-STEVENSON, W. G. Cancer metastasis and angiogenesis: an imbalance of positive and negative regulation. Cell, v. 64, p. 327-336, 2001.

PEREIRA, J.; et al. Papel da Célula Endotelial em Neoplasias Malignas Hematológicas. Revista Brasileira de Hematologia e Hemoterapia, v. 30, n. 3, p. 223-228, 2008.

PODAR, K.; ANDERSON, K. C. The pathophysiologic role of VEGF in hematologic malignancies: therapeutic implications. Blood, v. 105, n. 4, p. 83-95, out. 2005.

QUACH, H.; et al. Mechanism of action of immunomodulatory drugs (IMiDS) in multiple myeloma. Leukemia; v. 24, n. 1, p. 22-32, jan. 2010.

SILVA, T. H. A. Agentes Antitumorais Inibidores da Angiogênese - Modelos Farmacofóricos para Inibidores da Integrina anb3. Revista Brasileira de Ciências. Farmacêuticas, v. 43, n. 1, p. 1-17, 2007.

UCHIYAMA, $\mathrm{H}$.; et al. Characterization of adhesion molecules on human myeloma cell lines. Blood, v. 80, n. 9, p. 2306-2314, nov. 1992.

URASHIMA, M.; et al. Transforming growth factor-beta1: differential effects on multiple myeloma versus normal B cells. Blood, v. 87, n. 5, p. 1928-1938, mar. 1996.

ZHANG, $\mathrm{H}$; ; et al. Circulating endothelial progenitor cells in multiple myeloma: implications and significance. Blood, v. 105, n. 8, p. 86-94, apr. 2005.

ZHANG, X. G.; BATAILLE, R.; WIDJENES, K. B. Interleukin-6 dependence of advanced malignant plasma cell dyscrasias. Cancer, v. 69, p. 1373-1376, mar. 1992. 